\title{
Tsunami generation by horizontal displacement of ocean bottom
}

\author{
Yuichiro Tanioka \\ Dept. of Geological Science, University of Michigan, Ann Arbor
}

\section{Kenji Satake}

Seismotectonics Section, Geological Survey of Japan, Tsukuba

\begin{abstract}
Tsunami generation by an earthquake is generally modeled by water surface displacement identical to the vertical deformation of ocean bottom due to faulting. The effect of horizontal deformation is usually neglected. However, when the tsunami source is on a steep slope and the horizontal displacement is large relative to the vertical displacement, the effect becomes significant. We show this for two recent earthquakes which generated much larger tsunamis than expected from seismic waves. In the case of the 1994 June 2 Java, Indonesia, earthquake, the focal mechanism was a very shallow dipping thrust and the source was near a very steep trench slope. In the case of the 1994 Nov. 14 Mindoro, Philippines, earthquake, strike-slip faulting extended from ocean to land perpendicular to the coast line. In both cases, we found that the horizontal motion of slope had an important contribution to the tsunami generation.
\end{abstract}

\section{Introduction}

Numerical computations of tsunami caused by large earthquakes have been carried out on actual bathymetry by many researchers [e.g. Aida, 1978; Shuto, 1991; Satake, 1995]. The initial ocean surface condition is usually assumed to be identical to the vertical deformation of the ocean bottom due to faulting, based on three assumptions. First, tsunamis are assumed to be long waves, i.e., the wavelength is much larger than the water depth. This is because the fault size of a large tsunamigenic earthquake is several tens to hundreds of $\mathrm{km}$ while the ocean depth around the source area is at most several $\mathrm{km}$. For long waves, the vertical acceleration of water particles is neglected compared to the gravitational acceleration. This means that the water mass from the ocean bottom to the surface moves uniformly in horizontal direction. A more general description of surface deformation due to vertical deformation of ocean bottom is described by Kajiura [1981]. Second, the vertical deformation of ocean bottom is assumed to be instantaneous. This is because the phase velocity of a tsunami $(0.2 \mathrm{~km} / \mathrm{s}$ for a depth of $4000 \mathrm{~m})$ is much slower than the propagation velocity of earthquake rupture $(2-3 \mathrm{~km} / \mathrm{s})$. Third, the horizontal movement of ocean bottom due to faulting is assumed to be negligible in tsunami generation. This assumption is valid for faulting which occurs on a flat or shallowly-dipping ocean bottom. Berg et al. [1970] show that for a motion equivalent in magnitude to that of the 1964 Alaskan earthquake (Mw 9.2) and acting normal to the continental slope,

Copyright 1996 by the American Geophysical Union.

Paper number 96GL00736

0094-8534/96/96GL-00736\$05.00 the input potential energy from the horizontal movement is less than $1.5 \%$ of that from the vertical movement.

In this paper, we show that there are some exceptions to the third assumption and that horizontal displacement due to faulting can become important for tsunami generation. We show this with two recent earthquakes: the 2 June 1994 Java earthquake (Ms 7.2) which occurred along the Sunda trench in Indonesia (this earthquake had a very shallow-dipping fault plane with a thrust type mechanism), and the $14 \mathrm{Nov} .1994$ Mindoro earthquake (Ms 7.1) (strike-slip mechanism rupturing perpendicular to the northern coast of Mindoro Island in the Philippines). Both earthquakes generated much larger tsunamis than expected from the seismic waves and caused extensive damage near the coast. Study of the tsunami generation mechanism of these events is also very important for tsunami disaster prevention. The numerical computation of the tsunamis for these two earthquake are carried out to find the significance of the horizontal displacement due to faulting.

\section{Method}

Crustal deformation due to faulting can be calculated using elastic theory of dislocation. Steketee [1958] showed that the surface displacement $u_{k}$ on an elastic half-space due to a dislocation $\Delta u_{i}$ across a fault surface $\Sigma$ can be calculated as

$$
u_{k}=\frac{1}{F} \iint_{\Sigma} \Delta u_{i}\left[\lambda \delta_{i j} u_{k}^{n, n}+\mu\left(u_{k}^{i, j}+u_{k}^{j, i}\right)\right] v_{j} d \Sigma
$$

where $\lambda$ and $\mu$ are Lame constants, $\delta_{i j}$ is Kronecker's delta, $v_{j}$ is the direction cosine of the normal to the fault surface element $d \Sigma$, and $u_{k}^{i}$ denotes the $k$ th component of the surface displacement due to the $i$ th component of point force whose magnitude is $F$. An analytical solution of equation (1) (the horizontal displacements, $u_{x}$ and $u_{y}$, and the vertical displacement, $u_{z}$ ) for a finite rectangular fault [Okada, 1985] is used.

If earthquakes occur on a steep ocean slope, such as a continental-slope or a coastal slope, the horizontal displacement due to faulting moves the slope (see Figure 1b). In this case, there are two components of water motion to consider: vertical and horizontal motions of water due to the horizontal movement of the slope. The experimental study by Iwasaki[1982] shows that if the gradient of the slope is less than $1 / 3$, the tsunami generation due to the horizontal movement of the slope is dominated by the vertical motion of water, and the horizontal motion is negligible. Hence we ignore the horizontal motion of water due to the movement of slope, because most ocean bottom slopes, including steep slopes near the trenches, are less than 1/3.

The vertical displacement of water due to the horizontal movement of the slope, $u_{h}$, (shown in Figure 1 ) is calculated as 


\section{Initial condition of tsunami}

a) vertical movement due to faulting
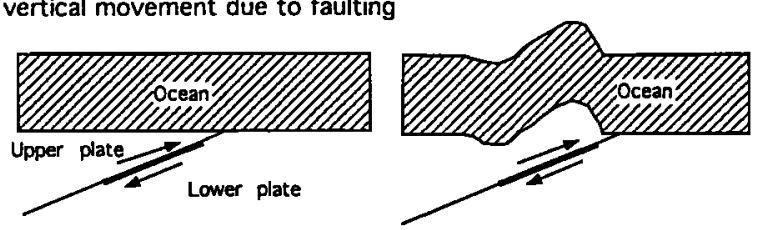

b) horizontal movement of slope
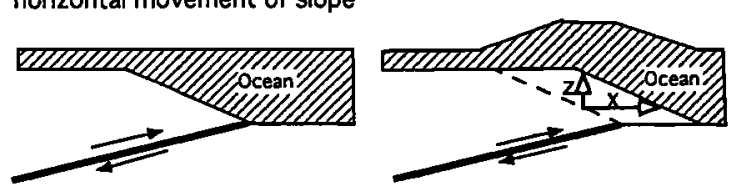

Figure 1. A schematic illustration of tsunami initial conditions for underthrust type earthquakes. The left side shows the ocean bottom before faulting and the right side shows the ocean bottom after faulting. Vertical displacement due to faulting is shown in (a). Horizontal movement of slope is shown in (b). Thick lines represent the regions where faulting occurs. Solid arrows show the fault motion. Open arrows show the vertical ( $z$ ) and horizontal $(x)$ motion of water due to the horizontal movement of slope.

$$
u_{h}=u_{x} \frac{\partial H}{\partial x}+u_{y} \frac{\partial H}{\partial y}
$$

where $H$ is the water depth and $u_{x}$ and $u_{y}$ are the horizontal displacements due to faulting. Note that $u_{h}$ is taken positive upward but $H$ is positive downward in equation (2). As mentioned before, the above expression is invalid for a very steep $(>1 / 3)$ slope. In an extreme case (such as a vertical cliff), the horizontal motion of water dominates the tsunami generation [Iwasaki, 1982], but such a case is unrealistic for earthquake tsunamis. The spatial derivative of water depth is computed using the central-difference scheme. Finally, the total vertical displacement, $u_{h}+u_{z}$, is calculated as the initial condition of tsunamis.

The method of tsunami numerical computation is described in Satake [1995]. The finite difference computation of the linear long wave equation and the equation of continuity on a staggered grid system is carried out on actual bathymetry data with a grid size of $20 \mathrm{sec}$. For comparison, the numerical computation from the initial condition of only vertical displacement, $u_{2}$, is also carried out.

\section{The 1994 Java earthquake}

The 2 June 1994 Java earthquake occurred off the southern coast of Java, Indonesia, along the Sunda trench. The NEIS Preliminary Determination of Epicenters (PDE) provides the source parameters: origin time, 18:17:34.0GMT; epicenter, $10.477^{\circ} \mathrm{S}, 112.835 \mathrm{E}$; depth, $18 \mathrm{~km}$; magnitude, Ms 7.2. It generated devastating tsunamis that killed more than 250 people on Java Island [Tsuji et al., 1995]. The focal mechanism of the 1994 Java event indicates thrust type faulting with a very shallow dip angle $\left(15^{\circ}\right)$ (Figure 2). The horizontal deformation due to faulting is larger than the vertical deformation. Aftershock distribution from the PDE catalog shows that the source area is very close to the Sunda trench axis and just beneath the steepest slope (Figure 2). The direction of horizontal motion near the steep slope is almost normal to the slope. Therefore, we expect

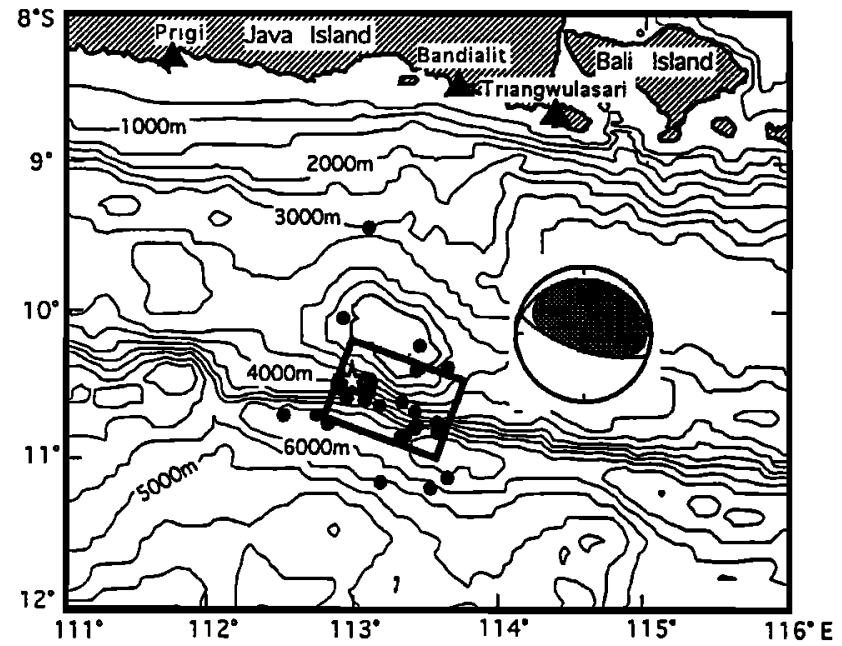

Figure 2. The bathymetry map near the epicenter (a star) of the 1994 Java earthquake with the focal mechanism and aftershock distribution (solid circles). The rectangle shows the fault model. Triangles show the locations where tsunami waveforms are computed.

that the horizontal movement of the slope may have significant contributions to the vertical displacement of water.

The fault model, shown in Figure 2, (length $90 \mathrm{~km}$, width 60 $\mathrm{km}$ ) is used to compute the tsunami initial condition. We use a pure thrust type fault (strike $=280^{\circ}, \operatorname{dip}=15^{\circ}$, rake $=90^{\circ}$ ). From the seismic moment of $3.5 \times 10^{20} \mathrm{Nm}$ of the Harvard CMT and a rigidity of $4 \times 10^{10} \mathrm{~N} / \mathrm{m}^{2}$, the average slip is calculated to be 3.24 $\mathrm{m}$. A comparison of the vertical displacement due to faulting $\left(u_{z}\right)$, the vertical displacement due to the horizontal movement of the slope $\left(u_{h}\right)$, and the total displacement $\left(u_{h}+u_{z}\right)$ is shown in Figure 3. The maximum amplitude of $u_{z}, u_{h}$ and $u_{h}+u_{z}$, are $1.02 \mathrm{~m}, 0.44 \mathrm{~m}$, and $1.29 \mathrm{~m}$, respectively; the maximum amplitude of $u_{h}$ is $43 \%$ of the maximum amplitude of $u_{z}$. Figure 4 compares the computed waveforms at three locations from two initial conditions, from the vertical displacement $u_{z}$ only and from the total vertical displacement $u_{h}+u_{z}$, The waveforms are

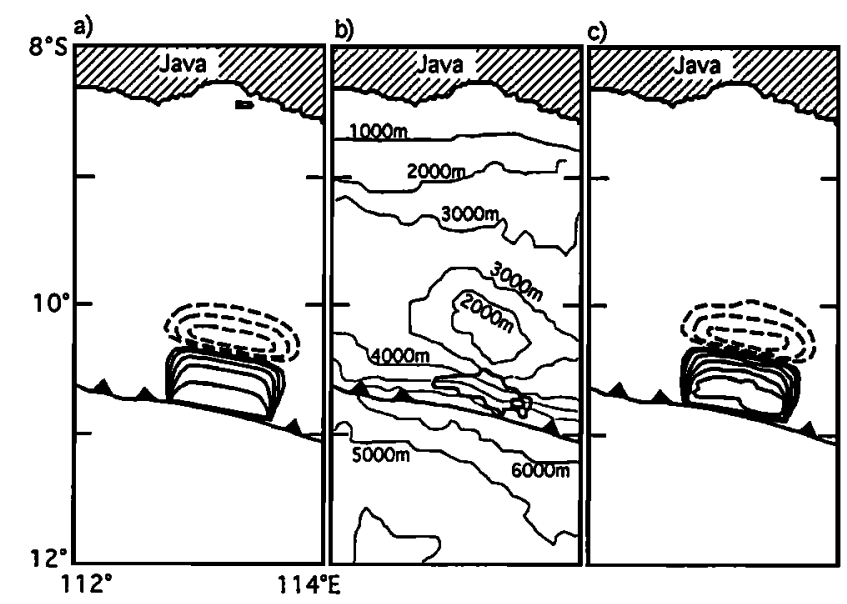

Figure 3. The comparison of (a) the vertical displacement due to faulting, (b) the vertical displacement due to the horizontal movement of the slope, and (c) the total displacement for the 1994 Java earthquake. Solid and dashed heavy contours are for uplift and subsidence, respectively, with a $20 \mathrm{~cm}$ interval. The bathymetry (light contours) is shown in (b). 


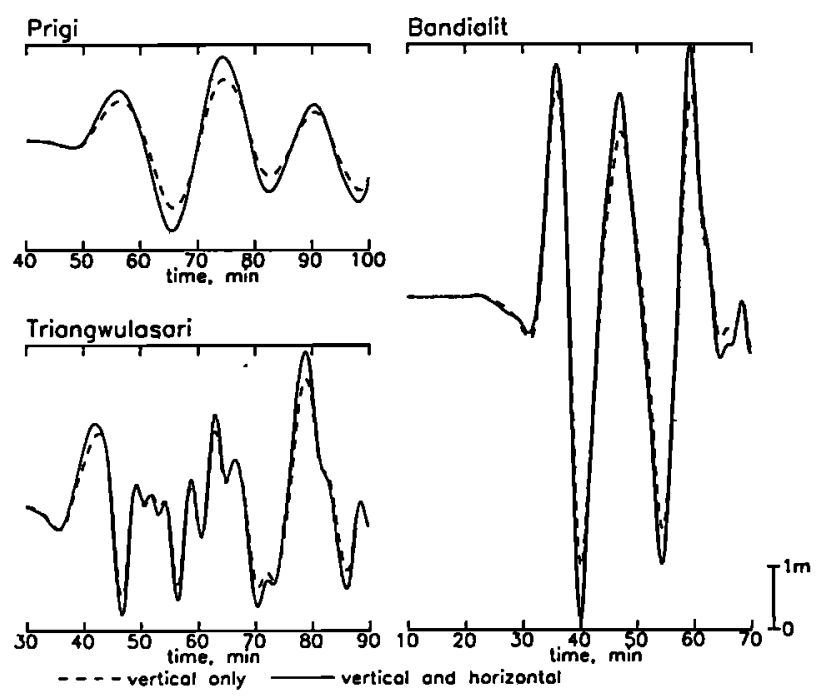

Figure 4. The comparison of the computed waveforms at Prigi, Bandialit and Triangwulasari for two different initial conditions, the vertical displacement due to the faulting (dashed curves) and the total vertical displacement (solid curves) caused by the 1994 Java earthquake.

very similar but the amplitudes are different. The amplitude difference is as much as $30 \%$. Therefore, the horizontal movement due to faulting is significantly important for the tsunami generation for the 1994 Java earthquake. The observed

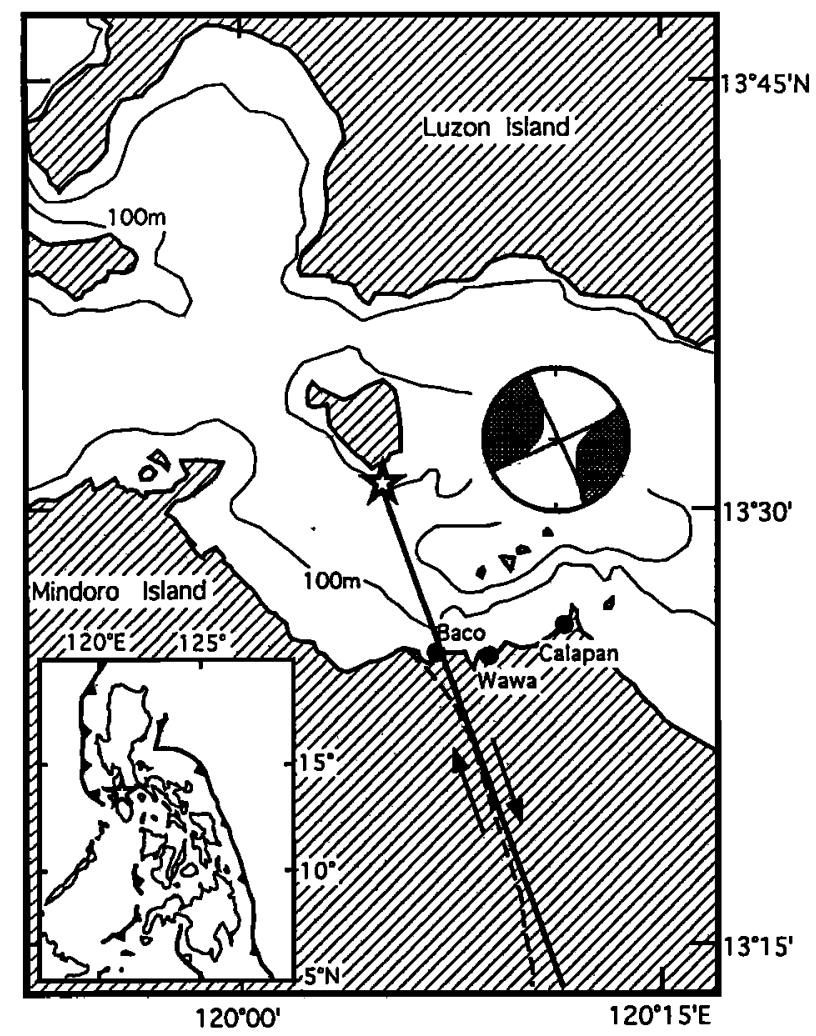

Figure 5. The bathymetry map near the epicenter (star) of the 1994 Mindoro earthquake with the focal mechanism. Inset shows the tectonic setting near the Philippines. A solid line shows the fault model. A dashed line shows where the surface ruptures are observed [PHILVOLCS Quick Response Teams, 1994]. Solid circles show where tsunami waveforms are computed . tsunami runup heights at three locations, Prigi, Bandialit, and Triangwulasari, (Figure 2) are 3-4 m, 5-10m, and 4-5m [Tsuji et al., 1995]. The computed maximum heights at these locations (Figure 4) are $1.1 \mathrm{~m}, 4.0 \mathrm{~m}$, and $2.7 \mathrm{~m}$, which are almost half of the observed tsunami heights. These discrepancies may become small if we use a finer grid system and include non-linear and run-up effects [Shuto, 1991; Satake and Tanioka, 1995].

\section{The 1994 Mindoro earthquake}

The 14 Nov. 1994 Mindoro earthquake occurred near the northern coast of Mindoro Island, Philippines. The NEIS PDE provides the source parameters: origin time, 19:15:30.7 GMT; epicenter, $13.532^{\circ} \mathrm{S}, 121.087 \mathrm{E}$; depth $33 \mathrm{~km}$; magnitude, Ms 7.1 . It generated devastating tsunamis that killed more than 70 people on Mindoro Island. Some surface rupture was observed on the northern part of Mindoro Island although the epicenter is located in the ocean (Figure 5) [Imamura et al., 1995]. The right lateral surface displacement measured by the Philippine Institute of Volcanology and Seismology (PHIVOLCS) was about $2 \mathrm{~m}$ [PHIVOLCS Quick Response Teams, 1994]. The focal mechanism is shown in Figure 5. It shows strike-slip type faulting. The surface rupture and the focal mechanisms indicate that the strike-slip faulting occurred almost normal to the slope of the coast. Like the 1994 Java earthquake case, we expect that the horizontal movement of the slope may have significant contributions to the vertical displacement of water.

The fault model, shown in Figure 5, with length and width of $35 \mathrm{~km}$ and $15 \mathrm{~km}$ respectively, are used to compute the initial condition of the tsunami. We assume a vertical right-lateral strike-slip fault (strike $=160^{\circ}$, dip $=90^{\circ}$, rake $=180^{\circ}$ ). We use the

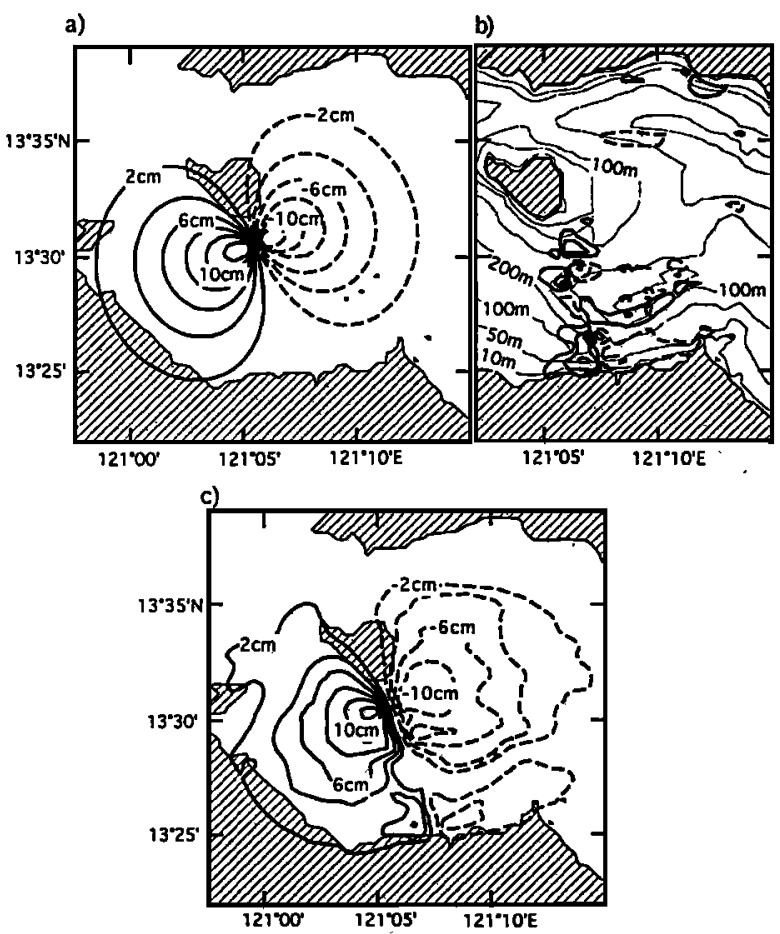

Figure 6. The comparison of (a) the vertical displacement due to faulting, (b) the vertical displacement due to the horizontal movement of the slope, (c) the total displacement for the 1994 Mindoro earthquake. Solid and dashed heavy contours are for uplift and subsidence, respectively, with a $2 \mathrm{~cm}$ interval. The bathymetry (light contours) is shown in (b). 


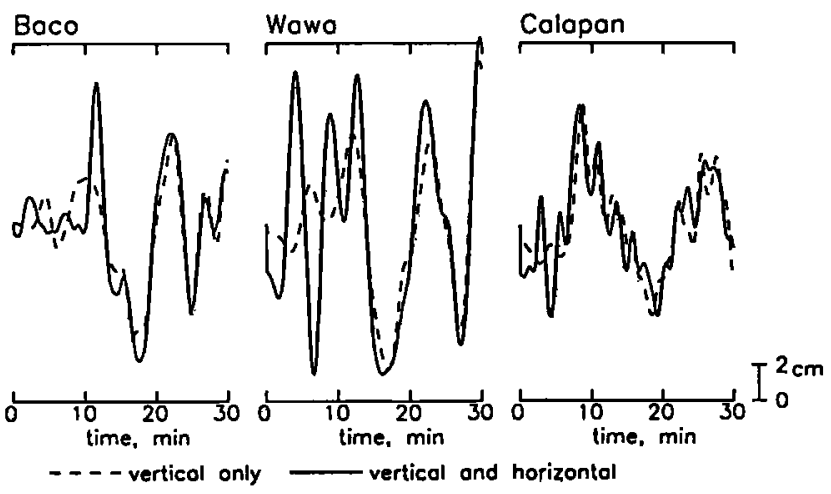

Figure 7. The comparison of the computed waveforms at Baco, Wawa and Calapan for two different initial conditions, the vertical displacement due to faulting (dashed curves) and the total vertical displacement (solid curves) caused by the 1994 Mindoro earthquake.

slip of $2 \mathrm{~m}$ from the observed surface displacement. A comparison of the vertical displacement due to faulting $\left(u_{z}\right)$, the vertical displacement due to the horizontal movement of the slope $\left(u_{h}\right)$, and the total displacement $\left(u_{h}+u_{z}\right)$ is shown in Figure 6. The maximum amplitudes of $u_{z}, u_{h}$, and $u_{h}+u_{z}$, are $0.14 \mathrm{~m}, 0.08 \mathrm{~m}$, and $0.13 \mathrm{~m}$, respectively. The maximum amplitude of $u_{h}$ is $57 \%$ of the maximum amplitude of $u_{z}$. Figure 7 compares the computed waveforms at three locations from two initial conditions, the vertical displacement due to faulting $u_{z}$ and the total displacement $u_{h}+u_{z}$ The two initial conditions produce maximum amplitudes which are similar but waveforms that are markedly different. Again, the horizontal movement due to faulting is as important as the vertical movement due to faulting. The computed maximum heights at three locations, Baco, Wawa, and Calapan (Figure 5) are $0.07 \mathrm{~m}, 0.09 \mathrm{~m}$, and $0.09 \mathrm{~m}$ (Figure 7). The observed tsunami runup heights are, however, much larger, 1-4 m, 1-4 m, and 2-3m at these locations [Imamura et al., 1995]. Another generation mechanism, such as landslide, may be necessary to explain the observed tsunami.

\section{Conclusion}

Horizontal displacement due to faulting becomes important for tsunami generation under two conditions; (1) large horizontal motion of a steep slope and (2) horizontal motion much larger than the vertical motion, such as a strike-slip faulting or a dip-slip faulting on a very shallowly dipping fault. This mechanism may be important for explaining tsunami earthquakes [Kanamori, 1972] which usually occurred near a trench axis.
Acknowledgments. We thank Jean Johnson and Nathan Winslow for helpful comments and Larry Ruff for constructive discussions and comments. This work was supported by NSF (EAR-9405767).

\section{References}

Aida, I., Reliability of a tsunami source model derived from fault parameters, J. Phys. Earth, 26, 57-73, 1978.

Berg, E., et al., Field survey of the tsunamis of 28 March 1964 in Alaska, and conclusions as to the origin of the major tsunami, in edited by Hawaii Institute of Geophysics, Honolulu, Hawaii, 1970.

Imamura, F., C.E. Synolakis, E. Gica, E. Titov, E. Listanco, and H.J. Lee, Field survey of the 1994 Mindoro Island, Philippines tsunami, Pure Appl. Geophys., 144, 875-890, 1995.

Iwasaki, S., Experimental study of a tsunami generated by a horizontal motion of a sloping bottom, Bull. Earthq. Res. Inst. Univ. Tokyo, 239$262,1982$.

Kajiura, K., Tsunami energy in relation to parameters of the earthquake fault model, Bull. Earthq. Res. Inst., Unix. Tokyo, 56, 415-440, 1981.

Kanamori, H., Mechanism of tsunami earthquakes, Phys. Earth Planet. Inter., 6, 246-259, 1972.

Okada, Y., Surface deformation due to shear and tensile faults in a halfspace, Bull. Seism. Soc. Am., 75, 1135-1154, 1985.

PHILVOLCS Quick Response Teams, The 15 November 1994 Mindoro earthquake, Report of Investigation, PHIVOLCS Special Report, No.2, 36 pp., 1994.

Satake, K., Linear and nonlinear computations of the 1992 Nicaragua earthquake tsunami, Pure Appl. Geophys., 144, 455-470, 1995.

Satake, K., and Y. Tanioka, Tsunami generation of the 1993 Hokkaido Nansei-oki earthquake, Pure Appl. Geophys., 144, 803-822, 1995.

Shuto, N., Numerical simulation of tsunamis-Its present and near future, in Tsunami Hazard, edited by E. N. Bernard, 171-191, Kluwer Academic, 1991.

Steketee, J.A., On Volterra's dislocations in a semi-infinite elastic medium, Can. J. Phys., 36, 192-205, 1958.

Tsuji, Y., F. Imamura, H. Matsutomi, C.E. Synolakis, P.T. Nanang, Jumadi, S. Harada, S.S. Han, K. Arai, and B. Cook, Field survey of the east Java earthquake and tsunami of June 3, 1994, Pure Appl. Geophys., 144, 839-854, 1995.

K. Satake, Seismotectonics Section, Geological Survey of Japan, Tsukuba, Ibaraki 305, Japan (e-mail: satake@gsj.go.jp)

Y. Tanioka, Dept. of Geological Sciences, Univ. of Michigan, Ann Arbor, MI 48109-1063. (e-mail: tanioka@umich.edu)

(Received November 20, 1995; revised January 15, 1996; accepted February 14, 1996.) 